Carmen Cavaco

Universidade de Lisboa, ULisboa, Portugal

E-mail: carmen@ie.ulisboa.pt

(1) https://orcid.org/0000-0001-8261-7650

\section{Reconhecimento e validação de adquiridos experienciais de adultos pouco escolarizados em Portugal: uma medida de política pública inovadora?}

\section{Carmen Cavaco}

\section{Resumo}

O texto analisa o processo de reconhecimento e validação de adquiridos experienciais, uma medida de política pública orientada para os adultos pouco escolarizados em Portugal. A análise resulta de uma investigação qualitativa baseada em entrevistas semiestruturadas com técnicos e formadores responsáveis pela implementação do processo em estudo e em entrevistas biográficas com adultos certificados através deste processo. Os dados empíricos recolhidos permitiram identificar alguns elementos de inovação no processo de reconhecimento e validação de adquiridos experienciais implementado em Portugal. No artigo, analisamos dois desses elementos de inovação, por um lado, o recurso à metodologia biográfica e à história de vida; por outro lado, o acompanhamento assegurado pelo técnico de orientação, reconhecimento e validação e pelos formadores. Na nossa perspectiva, os elementos de inovação identificados contribuem para que o processo de reconhecimento e validação de adquiridos experienciais orientado, do ponto de vista político, para o aumento da qualificação escolar dos adultos, apresente um potencial formativo nos adultos envolvidos.

Palavras-chave: Educação de jovens e Adultos. Aprendizagem. Pesquisas em EJA. 


\begin{abstract}
Recognition and validation of prior learning of low-educated adults in Portugal: is it an innovative public policy?

Keywords: Adult education policy. Youth and adult education.

Recognition of the prior learning.

This paper aims to analyze the process of recognition and validation of prior learning, a public policy measure meant for the low schooling adults in Portugal. This analysis is the result of a qualitative research based on semi-structured interviews with professionals responsible for implementing the process and on biographical interviews with adults certified through this process. The empirical data collected allowed us to identify some elements of innovation in the process of recognition and validation of prior learning in Portugal. This paper analyzes two elements of innovation: on the one hand, the use of the biographical method and life histories; and, on the other hand, the monitoring provided by the advisor and teachers, recognition and validation. In our point of view, the identified elements of innovation contribute so that the process of recognition and validation of prior learning, oriented, from the political point of view, increases the educational qualification of adults, presents a training potential in the adults involved.
\end{abstract}

Resumé

Mots-clés:

Politique

d'éducation des

adultes.

Éducation des jeunes et adultes. Reconnaissance des acquis de l'expérience.
Reconnaissance et validation des acquis de l'expérience des adultes peu scolarisés: une politique publique innovatrice?

L'article analyse le processus de reconnaissance et de validation des acquis de l'expérience, dans le cadre d'une politique publique orienté vers les adultes peu scolarisés, au Portugal. L'analyse est soutenue dans une recherche qualitative, développée à partir d'entretiens semi-structurés à professionnels responsables pour la mise en œuvre de ce processus et d'entretiens biographiques aux adultes certifiés. Les données empiriques recueillies ont permis d'identifier quelques éléments d'innovation dans ce processus de reconnaissance et de validation des acquis de l'expérience mise en œuvre, au Portugal. Cet article analyse deux éléments d'innovation, d'une part, l'usage de la méthode biographie et de l'histoire de la vie; d'autre part, la promotion de l'accompagnement des adultes, par des accompagnateurs qui sont aussi les responsables pour la mise en œuvre de la reconnaissance et de la validation des acquis de l'expérience des adultes. À notre avis, ces éléments d'innovation permettent de justifier les effets formatifs de cette mesure politique, au début seulement centré sur l'augmentation de la qualification scolaire des adultes. 


\section{Introdução}

Este artigo centra-se na análise do processo de reconhecimento e validação de adquiridos experienciais enquanto medida de política pública orientada para os adultos pouco escolarizados em Portugal. No artigo, usamos o termo adquiridos experienciais para designar os saberes - saber, saber-fazer e saber-ser - que a pessoa adquiriu ao longo da vida, em todos os tempos e espaços, na relação com os outros, com os contextos e consigo própria, os quais influenciam o seu modo de pensar, de ser e de agir. O processo de reconhecimento e validação de adquiridos experienciais é complexo, e a sua recente difusão no âmbito de políticas públicas contribuiu para a emergência de tensões e paradoxos (BERGER, 1991; CANÁRIO, 2006; JOBERT, 2005; LIÉTARD, 1997), que aumentam essa complexidade.

No artigo, procuramos analisar os domínios de inovação inerentes ao processo de reconhecimento e validação de adquiridos experienciais em Portugal, por partirmos do pressuposto de que esses domínios justificam a dimensão formativa do processo nos adultos implicados. Na nossa perspectiva, o processo de reconhecimento e validação de adquiridos experienciais, embora centrado, do ponto de vista político, na finalidade de certificação escolar dos adultos pouco escolarizados, apresenta uma dimensão formativa nos adultos envolvidos. Essa dimensão formativa do processo justifica-se, em grande medida, pelos elementos de inovação que estruturam o processo. A análise que se apresenta é a síntese dos resultados obtidos numa investigação qualitativa, focada no estudo das políticas públicas de educação de adultos em Portugal. Os dados empíricos que apoiam a análise são provenientes de recolha documental e da realização de entrevistas semiestruturadas com técnicos responsáveis pela implementação do processo de reconhecimento e validação de adquiridos experienciais e de entrevistas biográficas com adultos que obtiveram uma certificação escolar através desta medida política.

O processo de reconhecimento e validação de adquiridos experienciais consiste na identificação dos saberes adquiridos pelos adultos ao longo da sua vida, em todos os tempos e espaços, e na comparação desses saberes com os elementos que constam nos referenciais de competências-chave para cada nível de escolaridade. O reconhecimento consiste na explicitação e na valorização dos saberes decorrentes de aprendizagens realizadas ao longo da vida por parte do adulto, realizando-se através da elaboração, pelo adulto, de uma narrativa biográfica, com o acompanhamento dos formadores e de um técnico de orientação, reconhecimento e validação. O reconhecimento é realizado através da explicitação de saberes e da valorização que os adultos, o técnico e os formadores envolvidos atribuem a esses 
saberes, uma vez que o autorreconhecimento - valor atribuído pelos adultos aos seus saberes - não só depende mas também influencia o heteroreconhecimento - valor atribuído aos saberes do adulto pelo técnico e pelos formadores envolvidos no processo. Nesse sentido, o reconhecimento caracteriza-se por uma relação dialética entre a dimensão pessoal e social, na medida em que é necessário “[...] reconhecer-se para se fazer reconhecer” (AUBRET; MEYER, 1994). A interdependência entre o autorreconhecimento e o heteroreconhecimento é um fator que caracteriza este processo e também justifica a sua complexidade. A validação consiste na análise e na comparação dos saberes de cada adulto com os elementos que constam nos referenciais de competências-chave de cada nível de ensino. A certificação é a atribuição de um certificado que atesta o nível de qualificação escolar do adulto.

O processo de reconhecimento, validação e certificação de adquiridos experienciais baseia-se em três princípios: primeiro, a experiência tem um potencial formativo, sendo geradora de aprendizagens; segundo, num processo educativo, não é adequado pretender ensinar aos adultos o que já sabem; terceiro, é possível estabelecer comparação entre os saberes resultantes da experiência de vida e os saberes acadêmicos (BERGER, 1991; CANÁRIO, 2006; JOBERT, 2005). Estes princípios influenciam de um modo determinante a organização e o funcionamento das práticas de reconhecimento e validação de adquiridos experienciais e estão na base da complexidade deste processo. Ou seja, “[...] a partir do momento que se adoptam estes princípios que parecem razoáveis, as dificuldades começam e são consideráveis, tanto ao nível social como ao nível epistemológico" (JOBERT, 2005, p. $12)$.

As primeiras práticas de reconhecimento e validação de adquiridos experienciais surgiram entre 1950 e 1970, na sequência de exigências de movimentos sociais, nos Estados Unidos da América e no Canadá, e filiavam-se a uma “[...] tradição educativa humanista e personalista" (CANÁRIO, 2006, p. 42), com a finalidade do prosseguimento dos estudos, sendo orientadas para a valorização dos adultos. Contudo estas práticas não tiveram uma grande visibilidade social. A partir de 1995, no âmbito da perspectiva da aprendizagem ao longo da vida, o processo de reconhecimento e validação de adquiridos experienciais passou a ser contemplado nos documentos de política educativa da União Europeia e atingiu, progressivamente, uma grande notoriedade social (CAVACO, 2019). Em simultâneo, a Organização das Nações Unidas para a Educação, Ciência e Cultura (UNESCO, 1999), na V Conferência Internacional de Educação de Adultos, realizada em 1997, propôs também a criação de mecanismos coerentes para reconhecer os adquiridos experienciais, resultantes de 
aprendizagens realizadas em diferentes contextos. Nesse seguimento, em Portugal, o processo de reconhecimento e validação de adquiridos experienciais surgiu em 2000, no âmbito de um conjunto de medidas políticas orientadas para o aumento da qualificação escolar de adultos pouco escolarizados, sob a influência das orientações políticas da Unesco e da União Europeia (CAVACO, 2019).

Do ponto de vista político, o investimento no processo de reconhecimento e validação de adquiridos experienciais surgiu associado à importância do aumento da qualificação escolar e profissional dos jovens e dos adultos, na tentativa de minimização dos problemas do desemprego e de promoção da mobilidade profissional (CAVACO, 2019). No Livro Branco sobre a Educação e a Formação (COMISSÃO EUROPEIA, 1995), propõe-se a criação de dispositivos de reconhecimento, validação e certificação de competências para resolver o problema dos jovens que saem do sistema educativo sem diploma escolar e sem qualificação profissional. Este processo é associado às questões do emprego, pois “[...] a finalidade é a de permitir, por exemplo, a uma pessoa sem diploma que se apresente perante o empregador justificando competências acreditadas" (COMISSÃO EUROPEIA, 1995, p. 23). O documento refere a importância de dispositivos que contribuam para a promoção da mobilidade de pessoas entre os vários países da União Europeia e para o reconhecimento de competências adquiridas através da educação não formal e informal por parte de empregadores e de responsáveis por estabelecimentos de educação e formação. No plano político, a partir de então, fez-se uma aposta no reconhecimento e na validação de adquiridos experienciais. A instrumentalização do processo de reconhecimento e validação de adquiridos experienciais ao serviço do mercado de trabalho contribuiu para a emergência de "[...] um paradoxo que reside no facto de uma inspiração humanista estar associada a políticas e práticas de formação que contrariam essa inspiração fundadora” (CANÁRIO, 2006, p. 35), porquanto estão centradas na gestão dos recursos humanos e no desenvolvimento econômico. Este paradoxo é um elemento de complexidade, porque origina uma tensão permanente entre as finalidades, as opções metodológicas e os resultados do processo.

$\mathrm{Na}$ sua inspiração inicial, o processo de reconhecimento e validação de adquiridos experienciais estava associado a finalidades de desenvolvimento humano, contudo, nas atuais políticas públicas, surge ligado à gestão de recursos humanos no mercado de trabalho e ao desenvolvimento econômico. A instrumentalização do reconhecimento e da validação de adquiridos experienciais ao serviço da gestão de recursos humanos, numa lógica da competitividade econômica, gera um conjunto de perversões e de tensões em um processo fortemente inspirado, em termos teóricos e metodológicos, no humanismo. Desse modo, o 
processo de reconhecimento e validação de adquiridos experienciais, ao ser orientado, essencialmente, para as questões do emprego e da certificação, pode constituir "[...] as premissas de um novo modo de gestão social ao serviço das leis implacáveis da economia de mercado" (LIÉTARD, 1997, p. 74). Os dispositivos de reconhecimento e validação de adquiridos experienciais inscrevem-se "[...] num jogo de influências e de relação de forças nem sempre favoráveis ao indivíduo que adere ao processo" (LIÉTARD, 1997, p. 69), o que evidencia uma perversão da finalidade inicialmente associada a estes dispositivos - o desenvolvimento humano. Os métodos usados nos processos de reconhecimento e validação de adquiridos experienciais são inovadores, pois baseiam-se na valorização da experiência e dos saberes das pessoas, mas, por outro lado, as finalidades são focadas na adaptação dos indivíduos às exigências do mercado de trabalho e da economia. Esta "[...] contradição entre métodos e finalidades constitui o cerne da ambiguidade que define a situação paradoxal em que estão mergulhados os educadores e formadores de adultos" (CANÁRIO, 2006, p. 45) responsáveis pela implementação do processo de reconhecimento e validação de adquiridos experienciais. Neste artigo, procuramos analisar as dimensões inovadoras do processo, que permitem atenuar o paradoxo mencionado e transformar o reconhecimento e a validação de adquiridos experienciais num tempo e num espaço orientados para o desenvolvimento humano.

$\mathrm{O}$ artigo está organizado em três partes. A primeira parte foca-se na metodologia da investigação. A segunda parte apresenta uma síntese do processo de reconhecimento e validação de adquiridos experienciais realizado em Portugal. A terceira parte centra-se na análise de duas dimensões inovadoras do processo de reconhecimento e validação de adquiridos experienciais, que justificam o seu potencial formativo para os adultos certificados.

\section{Metodologia}

A investigação qualitativa centrou-se no estudo do processo de reconhecimento e validação de adquiridos experienciais, através da análise das orientações políticas da Comissão Europeia, da Unesco e do Estado Português, assim como da análise de quinze entrevistas semiestruturadas realizadas com técnicos que implementam o processo e de catorze entrevistas biográficas realizadas com adultos certificados. A investigação qualitativa foi inspirada, no plano epistemológico, essencialmente, pelos pressupostos da perspectiva fenomenológica. A perspectiva fenomenológica, como o próprio nome indica, centra-se no estudo dos fenômenos, com o pressuposto de que estes são construções que resultam da ação de atores sociais. Ou seja, entende-se que o "[...] mundo social não nos é dado, como 
postulam os positivistas, mas é constantemente construído pelos atores sociais" (LAPERRIÈRE, 1997, p. 311). Neste caso, a construção dos factos resulta de uma atribuição de sentido à realidade, que é mediada pelas nossas referências teóricas, esquemas de pensamento, experiências, interações com os outros e com o ambiente. Trata-se de uma abordagem aberta, que, ao defender o caráter construído dos fenômenos sociais, reconhece a contingência, a relação dialética sujeito/objeto e a importância de não se estabelecerem hipóteses à priori.

A perspectiva fenomenológica é "orientada para a descoberta", o seu objetivo é encontrar o sentido para os dados, numa atitude suficientemente aberta "[...] para deixar os significados imprevistos manifestarem-se" (GIORGI, 1997, p. 355). A fenomenologia pretende "deixar falar os fenômenos por si" (LAPERRIÈRE, 1997, p. 309). Porém privilegiar o vivido dos atores sociais para compreender a sua ação não significa que a investigação se centre necessariamente na descrição minuciosa das ações ou dos fenômenos através da sua observação e captação das dinâmicas. Nesta investigação, procuramos privilegiar a ação interpretada quer pelos atores, quer pelo investigador, o que justifica "[...] a importância da linguagem e da conceptualização" (DESLAURIERS; KÉRISIT, 1997, p. 90). Os atores sociais atuam em função de estímulos e de símbolos, e "[...] esses símbolos são a linguagem e as ações dos outros, elementos que os atores sociais definem e interpretam constantemente, de uma situação para outra, as suas próprias ações são o resultado dessas interpretações" (LAPERRIÈRE, 1997, p. 311). A fenomenologia é uma perspectiva compreensiva que consiste na interpretação global do significado atribuído pelos atores sociais à sua ação, tornando-se difícil "[...] distinguir o que foi observado daquilo que foi interpretado" (MUCCHIELLI, 2002, p. 34). Desse modo, a análise apresentada no artigo resulta da articulação entre a interpretação dos participantes e a interpretação realizada pela investigadora.

Durante a investigação, tivemos em conta os procedimentos éticos exigidos no âmbito das pesquisas realizadas no domínio das Ciências Sociais e Humanas, de acordo com a Carta Ética da Sociedade Portuguesa de Ciências da Educação (SPCE, 2014). No consentimento informado, os participantes foram devidamente esclarecidos sobre o tema, os objetivos, a metodologia, a finalidade da investigação e da recolha de dados e sobre a divulgação dos resultados. No consentimento informado, explicitamos os procedimentos éticos adoptados pelo investigador, de modo a proteger os dados de vida privada, a assegurar o anonimato e a possibilidade de desistência de participação em qualquer fase da pesquisa, assim como a devolução e a validação da transcrição das entrevistas realizadas. Ao longo da investigação, 
assumimos a importância de estabelecer relações de confiança, de empatia e de respeito entre a investigadora e os participantes.

Nesta investigação, baseamo-nos na premissa de que o investigador nas Ciências Sociais e Humanas é membro de uma comunidade e não pode abstrair-se da sua participação, o que significa que, independentemente do seu objeto de estudo e da sua metodologia, o trabalho que desenvolve "[...] afeta-o a si próprio, os outros e o mundo no qual participa" (SCHURMANS, 2006, p. 41). Ao longo desta investigação, adoptamos, sobretudo, uma postura de 'escuta' atenta aos atores sociais contactados, e não houve a preocupação de manter um distanciamento dos atores e das suas práticas, com o pretexto de uma pretensa objetividade. Pelo contrário, optamos por uma estratégia de 'escuta dialogante', assumindo que os momentos de realização das entrevistas constituem práticas sociais em que o investigador interage com os interlocutores e que quanto mais rica é essa interação mais possibilidades tem de obter a informação que lhe permita compreender a diversidade, a riqueza e a complexidade das práticas sociais e educativas em estudo. No contacto com os técnicos entrevistados, percebemos a importância de terem acesso aos resultados da pesquisa à medida que a análise avançava. Desse modo, ao longo da investigação, partilhamos a análise dos resultados através de documentos escritos e de reuniões de trabalho. Consideramos que estas estratégias constituem formas de "restituição do conhecimento científico" (SCHURMANS, 2014) aos atores que contribuíram para a sua produção, assegurando, desde logo, uma participação e uma relação com benefícios para todos os envolvidos no processo.

\section{Reconhecimento e validação de adquiridos experienciais: breve contextualização}

O processo de reconhecimento e validação de adquiridos experienciais, criado em 2000, passou a ser implementado nos Centros de Reconhecimento, Validação e Certificação de Competências, que atualmente são designados Centros Qualifica. Os Centros Qualifica são estruturas especificamente criadas para assegurar o acolhimento, o diagnóstico e a orientação dos adultos para as várias ofertas formativas e, em simultâneo, a implementação do processo de reconhecimento e validação de adquiridos experienciais. Os Centros Qualifica recebem financiamento para o desenvolvimento da sua missão por parte da Agência Nacional para a Qualificação e o Ensino Profissional, que os tutela. Os Centros Qualifica estão sediados em entidades da sociedade civil (associações, sindicatos), em entidades públicas (escolas, centros de formação, autarquias) e em entidades privadas (empresas). 
O processo de reconhecimento e validação de adquiridos experienciais ganhou visibilidade social progressivamente, em grande parte devido ao investimento político, mas também à elevada adesão e mobilização dos adultos pouco escolarizados. Em 2000, foram criados os seis primeiros Centros, e a rede foi aumentando, gradualmente, até 2005 (98 Centros). Contudo, a partir de 2006, ocorreu um aumento significativo (270 centros), o que viria a ser reforçado em 2008 (463 Centros). Atualmente, há 303 Centros Qualifica em funcionamento no país (PORTUGAL, 2011; COMISSÃO EUROPEIA, 2019).

O processo de reconhecimento, validação e certificação de adquiridos experienciais realizado nos Centros Qualifica é dirigido a adultos com mais de 18 anos que não possuem o $12^{\circ}$ ano de escolaridade. Os certificados atribuídos são referentes ao nível $\mathrm{B} 1$ ( $^{\circ}$ ano de escolaridade), B2 ( $6^{\circ}$ ano de escolaridade), B3 ( $9^{\circ}$ ano de escolaridade) e ao Ensino Médio ( $12^{\circ}$ ano de escolaridade). Os Centros Qualifica têm uma equipe composta por coordenador, formadores e técnicos de orientação, reconhecimento e validação de competências. Neles, a realização do processo de reconhecimento e validação de adquiridos experienciais é assegurada através da identificação dos saberes resultantes da experiência de vida, decorrentes de diversas dimensões (pessoal, familiar, social, profissional e escolar/formação profissional).

As equipes dos Centros Qualifica orientam o seu trabalho pelos referenciais de competências-chave do nível básico e do Ensino Médio. Estes referenciais de competênciaschave são distintos do currículo do ensino regular e foram concebidos especificamente para orientar e estruturar a oferta de educação de adultos. O referencial do Ensino Básico é constituído por quatro áreas de competências-chave (Matemática para a Vida, Linguagem e Comunicação, Cidadania e Empregabilidade e Tecnologias da Informação e Comunicação). Cada área de competência-chave é composta por três níveis de complexidade, aos quais correspondem os níveis de escolaridade passíveis de reconhecimento e de validação $\left(4^{\circ}\right.$ ano, $6^{\circ}$ ano e $9^{\circ}$ ano). O referencial do Ensino Médio é composto por três áreas de competênciaschave: Cidadania e Profissionalização; Sociedade, Tecnologia e Ciência; e Cultura, Linguagem e Comunicação.

A decisão sobre o nível de certificação a atribuir aos adultos depende, essencialmente, de dois fatores: por um lado, do nível de escolaridade que o adulto possui ao ingressar no processo, por outro lado, das competências que consegue demonstrar ao longo das várias fases deste processo. Para elucidar o trabalho realizado pelas equipes nos Centros Qualifica, elaboramos o seguinte fluxograma: 
Figura 1 - Fases do trabalho realizado nos Centros Qualifica

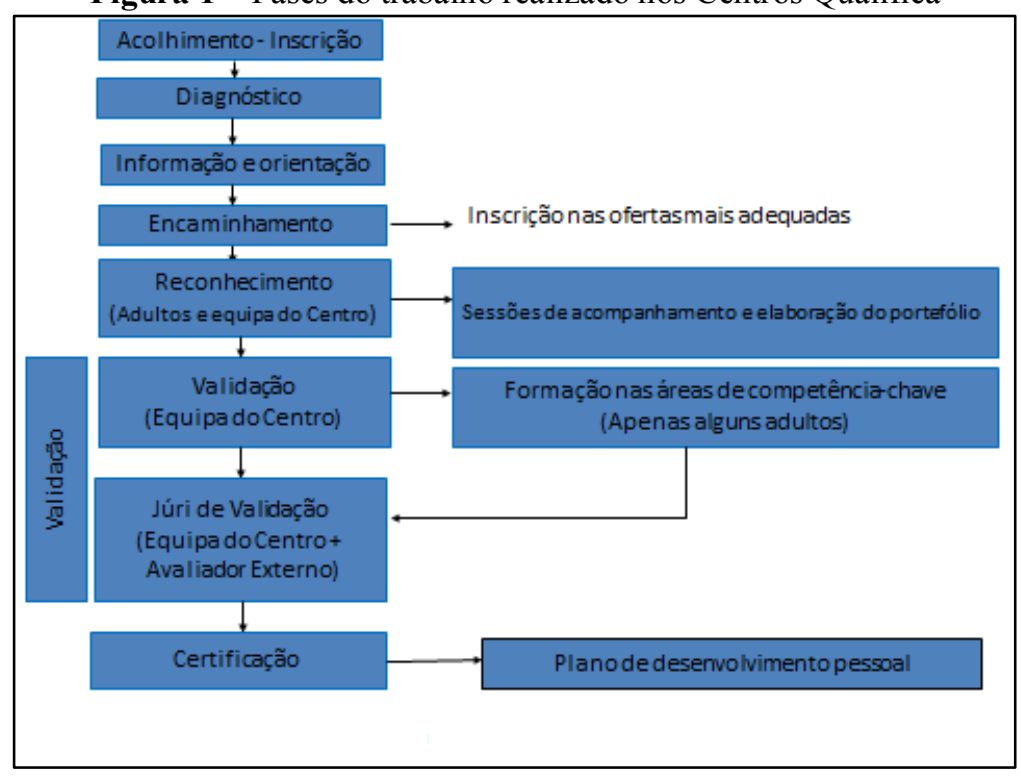

Fonte: elaborado pela autora.

Os adultos que se inscrevem nos Centros Qualifica passam obrigatoriamente pelas primeiras quatro fases apresentadas na Figura 1, com o apoio de técnicos de orientação, reconhecimento e validação de competências. Na fase de encaminhamento, os adultos podem ser orientados, em função do seu perfil e projeto de vida, para ofertas de educação escolar, para formação profissional e para o processo de reconhecimento, validação e certificação de adquiridos experienciais. Apenas os adultos encaminhados para este último processo continuam no Centro Qualifica e seguem para as fases posteriores.

Os dados estatísticos demonstram a elevada adesão dos adultos às medidas enquadradas nas políticas públicas de educação de adultos entre 2000 e 2017. De 2000 a 2010, inscreveram-se nestes Centros 1.316.955 adultos pouco escolarizados (PORTUGAL, 2011). Ou seja, as equipes dos Centros realizaram o diagnóstico, a orientação e o encaminhamento destes adultos para o conjunto de ofertas de educação de adultos existentes no país. Os adultos que usufruíram do diagnóstico, orientação e encaminhamento representam $21 \%$ dos adultos pouco escolarizados de Portugal e 14,6\% da população residente com mais de 15 anos. Entre 2000 e 2017, inscreveram-se no processo de reconhecimento e validação de adquiridos experienciais 1.171 .581 adultos e registou-se um total de 466.057 certificados de nível básico e/ou de Ensino Médio através do processo (PORTUGAL, 2011, 2018). Esses dados corroboram o elevado nível de adesão dos adultos pouco escolarizados às medidas enquadradas nas políticas públicas de educação de adultos de Portugal e o elevado número de adultos que obtiveram uma certificação escolar através do processo de reconhecimento e validação de competências nas últimas duas décadas. Porém, à semelhança do que defende José Gil (2012, p. 4), consideramos que, “[...] por baixo da informação tangível, dos números e das estatísticas, correm fluxos de acontecimentos inquantificáveis e que, no entanto, 
condicionam decisivamente a nossa vida". Importa mencionar que o processo de reconhecimento e validação de adquiridos experienciais realizado em Portugal, para além de permitir o aumento da qualificação escolar, também tem efeitos formativos nos adultos envolvidos. No ponto seguinte, pretendemos analisar dois elementos de inovação presentes no processo de reconhecimento e validação de adquiridos experienciais, os quais permitem que esta prática, do ponto de vista político, orientada apenas para a certificação escolar, seja, em simultâneo, um processo educativo para os adultos envolvidos.

Processo de reconhecimento e validação de adquiridos experienciais: elementos de inovação

Os dados empíricos recolhidos na investigação permitiram identificar alguns elementos de inovação no processo de reconhecimento e validação de adquiridos experienciais implementado em Portugal. Na nossa perspectiva, estes elementos de inovação, que se revelam estruturantes na organização e no funcionamento do referido processo, justificam a sua dimensão formativa nos adultos envolvidos. No decurso da investigação identificamos diversos elementos de inovação no processo de reconhecimento e validação de adquiridos experienciais, contudo, neste artigo, centramos a análise em dois domínios: i) o recurso à metodologia biográfica e à história de vida; ii) o acompanhamento assegurado pelos formadores e pelo técnico de orientação, reconhecimento e validação. Estes elementos de inovação contribuíram para a implementação de um processo complexo e com potencial formativo.

O processo de reconhecimento e validação de adquiridos experienciais, na sua essência, baseia-se na revalorização epistemológica da experiência de vida e dos adquiridos experienciais dos adultos, o que exige o recurso a modos de trabalho pedagógicos distintos do ensino tradicional - focado na transmissão de conhecimento. O processo de reconhecimento de adquiridos experienciais é realizado a partir de uma narrativa biográfica, centrada no percurso de vida do adulto. Ou seja, do ponto de vista metodológico, o processo de reconhecimento apoia-se na abordagem biográfica, nomeadamente nas histórias de vida. Para realizar o processo de reconhecimento, as equipes técnicas dos Centros precisam de ter acesso à informação sobre o percurso de vida do adulto, à sua experiência e aos seus adquiridos experienciais. Desse modo, o adulto é incentivado pelo técnico de orientação, reconhecimento e validação a falar e a escrever sobre o seu percurso de vida e os seus saberes. As falas dos adultos entrevistados confirmam a especificidade do processo de reconhecimento e validação de adquiridos experienciais e o seu distanciamento da "forma escolar" (CANÁRIO, 2005) tradicional: 
Não estão ali para ensinar. Nós é que temos que redescobrir aquilo que somos, é basicamente isso. Na escola, não; o professor dá a matéria e nós sabemos ou não. Ali, não, foi mais uma questão de nós tirarmos cá para fora aquilo que somos, aquilo que fazemos. (Adulto).

[É para] pôr a pessoa a falar de si própria. Neste caso, uma pessoa, quando está na escola, é muito mais jovem e está ali para aprender. Na minha situação e na de outras pessoas, a pessoa já vai falar daquilo que aprendeu, do que sabe, do que aprendeu ao longo da vida. (Adulto).

É uma coisa que não se estuda, é o nosso pensamento [...]. Se for uma matéria de escola, tem que estudar, apresentar. Este teste é completamente diferente. Não estamos aprendendo, nós é que estamos mostrando o que sabemos, eles não nos estão ensinando nada. (Adulto).

Não é nada de escola, não se vai aprender praticamente nada [...]. É diferente. Aqui não se aprende nada, não há quem ensine nada, vamos para ali e pedem o que nós sabemos. (Adulto).

O adulto elabora uma narrativa sobre a sua história de vida, na qual identifica os momentos, os contextos e as pessoas significativas, assim como as aprendizagens que realizou ao longo do percurso de sua vida. A elaboração da história de vida exige do adulto reflexão, rememoração, seleção e (re)elaboração da experiência. O processo de reconhecimento incide na biografização enquanto “[...] atividade psico-cognitiva de configuração temporal e narrativa, através da qual os homens dão uma forma específica ao seu percurso e às suas experiências da sua vida" (DELORY-MOMBERGER, 2014, p. 16). As falas dos adultos, dos técnicos e dos formadores confirmam a importância da escrita, da reflexão e da (re)elaboração da experiência no portfólio que elaboram com a sua história de vida, documento estruturante no processo:

Eu escrevi imenso, nunca tinha escrito tanto na minha vida, mesmo na escola. Aquilo para escrever... escreve, escreve, escreve. (Adulto).

Escrevia-se muito, muito. (Adulto).

Tens que fazer um dossier pessoal. (Adulto).

Aquele dossier é o ponto-chave do processo. Com o dossier, eles ficam a conhecer a nossa vida, a nossa experiência de vida e aonde é que a gente pode chegar. (Adulto).

Eles queriam conhecer a pessoa profundamente e pediam-nos para descrever o que aprendiamos, o que fazíamos. Havia um sentido de nos conhecerem profundamente. (Adulto).

Isto obriga-os a aprender a sintetizar informação e a esquematizar. (Técnico de orientação, validação e certificação).

$O$ dossier é que deve ser o instrumento fundamental para a validação de tudo. (Formador).

A biografização realizada pelos adultos no reconhecimento de adquiridos experienciais permite a elaboração da sua história de vida e a análise dos saberes decorrentes da sua experiência. A biografização presente na elaboração da história de vida possibilita ao adulto a compreensão do modo como se formou, assim como a análise da importância das outras pessoas na sua formação (heteroformação) e a importância dos contextos (ecoformação). Durante o processo de reconhecimento de adquiridos experienciais, através da biografização, o adulto compreende que a formação é uma dimensão natural no ser humano, 
que está presente em todos os tempos e espaços de vida, que é concomitante com os processos de socialização e influenciada por fatores sociais, culturais, econômicos e políticos que marcam a vida de cada sujeito. Todavia, através da elaboração da narrativa biográfica, também se apercebem da especificidade do seu percurso de vida e dos seus adquiridos experienciais, assim como da relevância do processo de apropriação individual do vivido, ou seja, da autoformação (PINEAU, 1988). Os adultos e os técnicos entrevistados colocam em evidências estas dimensões nas suas falas:

Apercebi-me que tinha aprendido no dia a dia. (Adulto).

[Apercebi-me de um conjunto de saberes que possuía] e a que eu não dava importância. (Adulto).

Senti que aprendi o que não sabia. Sabia e pensava que não sabia. Aprendi que sabia. Sabia muitas coisas. (Adulto).

Eu nunca tinha pensado que utilizava estas quatro áreas-chave na minha vida, no dia a dia. (Adulto).

Este ensinamento é muito importante na vida das pessoas, porque consegue ir buscar ao baú tudo o que lá estava acumulado. Nós nem nos apercebemos dos conhecimentos que temos. (Adulto).

Acho que aprendi bastante. Algumas coisas já sabia, mas estavam adormecidas. Acima de tudo, transmitiu-me confiança em mim própria. (Adulto).

Descobri coisas em mim a que não dava valor. Descobri coisas que para mim eram a rotina, que não me apercebia do valor que tinham, e que nem todos possuíam aqueles saberes. Nem todos sabiam fazer o que eu sei. [...] Achava que era normal saber. Depois descobri que era preciso ter certas competências para fazer o que fazia, nunca me tinha apercebido que tinha essas competências. (Adulto).

Tomaram consciência de situações que consideravam sem importância [...] aprenderam porque [o processo] as despertou de alguma forma para qualquer coisa que era importante. (Técnico de orientação, reconhecimento e validação).

Durante o reconhecimento de adquiridos experienciais, os adultos compreendem que a formação é um processo resultante das experiências que cada um teve, nos mais diversos tempos e espaços de vida, que, embora dependa da relação com os outros e da influência dos contextos, é sempre determinada pelo modo como cada pessoa se apropria e atribui sentido ao vivido. O próprio reconhecimento de adquiridos experienciais, ao incidir na reflexão sobre o percurso de vida e na explicitação dos saberes adquiridos, tem inerente a si um importante processo de autoformação, porquanto o adulto toma consciência dos seus saberes e do modo como foi realizada a sua aprendizagem. Esta dinâmica é notória nas falas dos adultos entrevistados identificadas anteriormente. Desse modo, o processo de identificação e explicitação dos adquiridos experienciais, com a finalidade de reconhecimento e validação, é, simultaneamente, um processo de formação. Em vista disso, os adultos constatam que têm um papel determinante na sua formação e sentem-se, progressivamente, mais capazes para investir em determinados tipos de aprendizagens e para concretizar os seus projetos de vida. A elaboração da história de vida através da biografização permite aos adultos sentirem-se os sujeitos das suas vidas e das suas formações, o que promove um sentimento positivo de 
valorização de si próprios (LIETARD; PIAU; LANDRY, 2017), bem como reconhecerem-se como sujeitos capazes de pensar e de agir, o que é destacado nas suas falas:

Eu fiquei muito feliz, porque ainda tenho essa capacidade [de aprender]. Fiquei com mais confiança em mim própria e acho que me soltei. Senti um crescimento tão grande! (Adulto).

Foi o iniciar de uma vida nova, porque eu tinha ficado adormecida. Não pensei que ia alterar a minha maneira de ser, a minha forma de estar [mas isso aconteceu]. (Adulto).

Eu próprio, ao ler as coisas que escrevi, fiquei orgulhoso de mim próprio. Descobri que, se calhar, era ainda melhor do que aquilo que eu pensava que era. (Adulto).

Os adultos entrevistados revelam que o processo de reconhecimento e validação de adquiridos experienciais teve um conjunto diversificado de consequências nas suas vidas, que diferem de adulto para adulto. Contudo, após a certificação, regista-se um efeito transversal a todos os adultos - a realização pessoal, que se traduz no aumento da confiança em si próprios e na elevação da autoestima. Este resultado tem impacto sobre todos os domínios da vida dos adultos, porque interfere na sua "dimensão existencial" (RICOEUR, 2004). Os adultos sentem que a reflexão e a escrita sobre o seu percurso de vida e os seus adquiridos experienciais lhes permitiram um balanço retrospectivo, com uma grande importância na orientação do seu futuro. Através desse processo, os adultos tomam consciência dos seus saberes, da sua capacidade de aprendizagem e do seu "poder de ação" (RICOEUR, 2005). Alguns adultos decidiram continuar a estudar - inscreveram-se no Ensino Médio ou candidataram-se a cursos no Ensino Superior. Os adultos destacam alterações positivas na relação com o saber, com os outros e consigo próprios. Esta multiplicidade de efeitos do processo de reconhecimento e validação de adquiridos experienciais é visível nas falas dos adultos:

Fiz o $10^{\circ}$ ano, este ano já estou no $11^{\circ}$ ano, já fiz umas 12 Unidades [...]. Se calhar, deram-me força para continuar a estudar. (Adulto).

[A obtenção do $9^{\circ}$ ano] levou-me novamente para o recorrente, para fazer $o$ secundário, estou a concluir o secundário, estou no $12^{\circ}$ ano. (Adulto).

Fui para ali, parece que a minha mente se começou a desenvolver mais [...] Eu leio os jornais... Comecei a ler mais depois de ir ao Centro, habituei-me a ler, porque eu tinha problemas em perceber. (Adulto).

Hoje vejo que tenho muito mais facilidade na escrita, não pareço a mesma [...]. A minha cabeça abriu-se. Parece que se fez luz! Eu fiquei a ver as coisas de outra maneira, mesmo a interpretar [...]. Agora comecei a ficar muito mais atenta a certas coisas, às notícias e até mesmo a ler o jornal. [Agora] gosto de ler o jornal, para estar minimamente informada. (Adulto).

O acompanhamento promovido pelo técnico de orientação, reconhecimento e validação, assim como pelos formadores, é um elemento fundamental na organização e no funcionamento do processo de reconhecimento e validação de adquiridos experienciais e, na nossa perspectiva, constitui um elemento de inovação desta medida política. Cada adulto é acompanhado por um técnico de orientação, reconhecimento e validação e pelos formadores 
das várias áreas de competência-chave, desde a sua inscrição no Centro até ao momento do júri de validação. O acompanhamento consiste na ideia de "caminhar ao lado" do adulto (LE BOUËDEC, 2002, p. 14). Neste tipo de acompanhamento, o adulto é considerado “[...] o ator principal que, de uma forma ou de outra, se pretende apoiar, proteger, servir, ajudar a chegar a um objetivo, sem nunca se suplantar ou ultrapassar, assumindo o seu lugar" (LE BOUËDEC, 2002, p. 14). O acompanhamento exige da equipa técnica uma "[...] postura modesta, de estar ao lado de, de colocar em valor e em destaque" o adulto (LE BOUËDEC, 2002, p. 15). As falas dos entrevistados elucidam a postura adoptada no acompanhamento do processo de reconhecimento e validação de adquiridos experienciais:

Costumo dizer que a responsabilidade aqui não é só minha, há corresponsabilidade. [Digo-lhes:] - Eu oriento os meus amigos e os meus amigos participam ativamente. É essa dialética que há. (Técnico de orientação, reconhecimento e validação).

O meu papel é ser um mediador. O protagonista do processo não posso ser eu. $O$ protagonista do processo tem que ser o próprio adulto. (Técnico de orientação, reconhecimento e validação).

O processo tem que ser centrado na reflexão que a pessoa faz sobre o seu próprio percurso de vida, e não na interpretação que eu faço do mesmo. (Técnico de orientação, reconhecimento e validação).

A minha função é ajudar, mas tem que partir deles. (Técnico de orientação, reconhecimento e validação).

Ela [explicava o que se pretendia] e depois nós fazíamos, quando as pessoas tinham dificuldade, ela estava sempre a ver. (Adulto).

A Dr. ${ }^{a}$ esclarecia, mas não diretamente, não dava a resposta. A mim uma dúvida ou outra que tive, ela ajudou-me a contorná-la, sem me pegar na mão, mas era o suficiente para eu captar. (Adulto).

O processo de reconhecimento e validação de adquiridos experienciais é desconhecido e difícil para o adulto. Nesse sentido, o acompanhamento da equipa técnica é determinante para que possa, progressivamente, compreender a especificidade do processo e envolver-se na reflexão, na explicitação e na (re)elaboração da experiência de vida, através da elaboração de uma narrativa biográfica. Quando se inscreve no Centro Qualifica, o adulto desconhece a organização e o funcionamento do processo de reconhecimento e validação de adquiridos experienciais, o que justifica o acompanhamento da equipa técnica, como se percebe nas falas dos entrevistados:

Tinha receio de ir e falhar. Era o meu medo, depois acabei por ir. Vou, é uma incógnita, não sei o que é que eu vou encontrar. (Adulto).

Eu chegar lá, sem ainda nunca ter visto um dossier, nem saber o que é que é, não é fácil. A gente tinha uma ideia, mas não sabia. Eu ouvia falar, mas não sabia o que é que aquilo era. (Adulto).

Há uma questão que procuro não esquecer. Às vezes esqueço-me disso, mas tento não o fazer, que é ter a noção que as pessoas vêm para aqui e vão encontrar uma coisa que não sabem o que é. (Técnico de orientação, reconhecimento e validação).

Após a superação das dificuldades relacionadas com a compreensão das caraterísticas do processo, o adulto confronta-se, frequentemente, com obstáculos na reflexão e na escrita 
sobre o seu percurso de vida, o que exige o acompanhamento da equipe. $\mathrm{O}$ recurso à metodologia biográfica (DELORY-MOMBERGER, 2014) no processo de reconhecimento de adquiridos experienciais torna-se exigente e difícil para os adultos, o que fundamenta a importância do acompanhamento por parte de técnicos com a formação adequada, como se verifica nas falas dos entrevistados:

Não é fácil, a gente chegar lá e escrever. (Adulto).

Havia perguntas com que às vezes era confrontado que não me saíam logo, tinha que refletir um pouco sobre elas para conseguir responder de acordo com aquilo que me era pedido. (Adulto).

A principio não era capaz de escrever. Fiquei a olhar, e as palavras não saíam para eu pôr no papel. Era pôr no papel o que estava a pensar, as frases. Não conseguia, fiquei assustada. (Adulto).

A Dr. ${ }^{a}$ viu que eu estava em pânico e disse: - Não escreve aqui, escreve lá em casa, com mais calma! (Adulto).

Ficam assustados, principalmente porque vão ter de falar sobre eles. (Técnico de orientação, reconhecimento e validação).

É muito complicado passar para o papel aquilo que se diz a nível oral. Pessoas que não estão habituadas a um percurso escolar, a escrever, desenvolveram muito mais competências ao nível da oralidade [do que na escrita]. (Técnico de orientação, reconhecimento e validação).

A estrutura e o conteúdo da narrativa biográfica são também domínios de dificuldade para os adultos. A narrativa biográfica é o documento de base para a identificação e explicitação dos adquiridos experienciais do adulto, a partir do qual tem lugar o processo de reconhecimento. $\mathrm{O}$ adulto precisa de um acompanhamento personalizado por parte da equipe, de modo a fazer com que a reflexão e a escrita sejam orientadas para os elementos passíveis de articulação com os referenciais de competências-chave, como se percebe nas falas dos entrevistados:

\footnotetext{
A gente tem que entender o que é que as pessoas querem que a gente responda. Depois de me aperceber do que é que elas queriam, estava à vontade. (Técnico de orientação, reconhecimento e validação).

Passadas umas três sessões, comecei logo a ver que eles iriam querer que nós fossemos desenvolver os nossos conhecimentos, que nem nos apercebíamos que os tínhamos, foi isso que eu vi. (Técnico de orientação, reconhecimento e validação).

Percebi perfeitamente aquilo que era pedido. [A Dr. ${ }^{a}$ dizia:] - O senhor responde aquilo que a gente quer que responda! Disse-me isso duas ou três vezes. (Técnico de orientação, reconhecimento e validação).

Há pessoas que, no final do processo, nós sentimos claramente que não entendeu a $100 \%$ do que se pretendia. (Técnico de orientação, reconhecimento e validação)
}

Os adultos pouco escolarizados subestimam, com frequência, os seus percursos de vida e adquiridos experienciais, tornando-se fundamental um acompanhamento sistemático durante a identificação e explicitação dos seus saberes. $\mathrm{Na}$ (re)elaboração da experiência, os adultos passam em silêncio o que parece sem valor e privilegiam o que parece ter muito valor. Os adultos pouco escolarizados tendem a 'passar em silêncio' muitos períodos e acontecimentos da sua vida, porque não lhes conseguem atribuir o devido valor. A atribuição 
de valor aos percursos e adquiridos experienciais está intimamente relacionada com a interpretação e o valor que cada pessoa atribui à sua vivência, mas também com o valor que o adulto percebe que os outros lhe conferem. A atribuição de valor inerente ao reconhecimento é um processo eminentemente social, pois “[...] o sentido particular atribuído por cada um à sua própria experiência adquire-se e valida-se através da interação e da comunicação humana" (MEZIROW, 2001, p. 16). Ou seja, o reconhecimento ocorre através de uma relação de interdependência dialética entre o autorreconhecimento (reconhecimento por si) e o heteroreconhecimento (reconhecimento pelo outro) (RICOUER, 2005), e o acompanhamento tem um contributo decisivo nesta dinâmica. O autorreconhecimento é decisivo para o envolvimento do adulto na (re)elaboração da experiência. Para Sansregret (1988, p. 23), “[...] determinada parte da experiência adquiriu assim um valor, mais ou menos positivo para o indivíduo, e esse valor influencia o comportamento de cada um na elaboração da sua experiência". O acompanhamento realizado pela equipa técnica dos Centros Qualifica é necessário para assegurar o processo de reconhecimento na sua dialética, uma vez que a socialização da experiência de vida e dos adquiridos experienciais contribui para o heteroreconhecimento e para o autorreconhecimento. Quando desvaloriza a sua experiência, o adulto não está em condições de "reconhecer-se para se fazer reconhecer". Neste caso, é necessário apostar no processo inverso: "ser reconhecido para reconhecer-se", estratégia que é adoptada pela equipa técnica durante o acompanhamento, como se poder ver nas falas dos entrevistados:

Eu penso sempre que sou pior que toda a gente. (Adulto).

Para mim aquilo não tinha grande valor, era o meu passado, não me dizia nada e trabalhei em muitos sítios, mas não me dizia nada. (Adulto).

Fazia-me ver as coisas de outra forma, ver a importância que as coisas tinham, eu talvez não lhe soubesse dar essa importância [...] a gente às vezes não sabe bem as competências que tem para realizar as coisas. (Adulto).

Por vezes, eu estou a dizer às pessoas: - Isso tem valor! E a pessoa diz-me: - "Tem valor no quê? Isto não tem valor nenhum." - Não consegue reconhecer o valor no que fez? - "Não!!! Não consigo reconhecer, porque não tem valor nenhum." (Técnico de orientação, reconhecimento e validação).

[Relato de uma adulta] No outro dia discuti com o meu marido e disse-lhe: - Tu devias ir assistir com a Dr. ${ }^{a}$ [refere nome da técnica], que era para veres ela a valorizar-me, porque há 30 anos que ouço da tua boca que não sirvo para nada e agora, afinal, vejo que até tenho valor. (Técnico de orientação, reconhecimento e validação).

A própria sociedade a desvaloriza. São os outros que lhe dizem: - És uma burra, não sabes nada, só fizestes a $4^{a}$ classe! [...] E a pessoa, quando procura um emprego, não pode, porque não tem o $6^{\circ}$ ou o $9^{\circ}$ ano. Vai-se inscrever num curso, não pode, porque não tem. É sempre excluída, porque não tem. A pessoa acredita toda a vida que não tem nada. (Técnico de orientação, reconhecimento e validação). As pessoas sabem mais do que pensam [e nós temos que lhes mostrar isso]. (Técnico de orientação, reconhecimento e validação).

Quando são pessoas que se desvalorizam muito e que não atribuem a menor importância às competências que têm, eu confronto-as com competências do referencial, para aumentar um pouco a autoestima delas e motivá-las um pouco 
mais para o processo, e fazê-las crer que têm capacidades para continuarem o processo. (Técnico de orientação, reconhecimento e validação).

Temos que confrontar a pessoa com os seus próprios conhecimentos, para que ela consiga reconhecer metade daqueles que tem, ou dar valor a metade dos que tem. (Técnico de orientação, reconhecimento e validação).

O investimento no acompanhamento do adulto permite contrariar a tendência de predomínio da lógica de gestão de recursos humanos, em que se inscrevem, do ponto de vista político, os dispositivos de reconhecimento e validação de adquiridos experienciais, porque estes são “[...] um meio mais rápido e menos dispendioso de obtenção dos diplomas e qualificações" (PIRES, 2006, p. 567) ao serviço do mercado de trabalho. O acompanhamento garantido pela equipe técnica dos Centros Qualifica é essencial para o adulto realizar com sucesso o processo de reconhecimento e validação de adquiridos experienciais e para que este tenha efeitos formativos, com impacto positivo em diversos domínios da sua vida.

\section{Conclusão}

A análise dos dados empíricos recolhidos com a equipe técnica dos Centros Qualifica e com os adultos certificados permite afirmar que processo de reconhecimento e validação de adquiridos experienciais é complexo, mas apresenta um potencial formativo muito importante para os adultos envolvidos. Do ponto de vista político, o processo de reconhecimento e validação de adquiridos experienciais tem como finalidade aumentar a qualificação escolar e profissional dos jovens e dos adultos, para assegurar mão de obra qualificada, promover a mobilidade profissional e contribuir para o desenvolvimento econômico. Neste caso, o referido processo é uma medida política orientada para a racionalidade econômica e instrumental, que se assenta na "[...] responsabilidade privatizada de construir biografias significativas" (FINGER; ASÚN, 2003, 118) e na "capitalização econômica do self" (ROSE, 1999, p. 161). Todavia os pressupostos e a complexidade do processo de reconhecimento e validação de adquiridos experienciais impulsionam o recurso a metodologias e a procedimentos filiados na valorização das pessoas e orientados para o desenvolvimento humano.

Através da análise apresentada, podemos concluir que as práticas de reconhecimento e validação de adquiridos experienciais, embora orientadas, do ponto de vista político, para a certificação, permitem o desenvolvimento de um processo formativo que se traduz em resultados diversificados e significativos para a vida dos adultos. $\mathrm{Na}$ análise, procuramos tornar evidente a existência de dois domínios de inovação nos processos de reconhecimento e validação de adquiridos experienciais que justificam a sua dimensão formativa - o recurso à 
metodologia biográfica e o investimento no acompanhamento do adulto por uma equipe técnica com formação específica.

O processo de formação ocorre devido às caraterísticas da metodologia biográfica e ao acompanhamento da equipe técnica. O recurso à metodologia biográfica, através da elaboração de um portfólio centrado na narrativa biográfica e na história de vida do adulto, visa à identificação e à explicitação das aprendizagens realizadas. A narrativa biográfica, orientada para a reflexão sobre o percurso de vida e os adquiridos experienciais, desencadeia um importante processo de formação nos adultos, porquanto permite a identificação e a apropriação do vivido. Na elaboração da narrativa biográfica, o adulto é confrontado com o seu percurso de vida, com os seus saberes e modos de aprendizagem, num processo marcado pela globalidade temporal - passado, presente e futuro. A reflexão e a socialização do vivido, que têm lugar na biografização realizada pelo adulto, dão origem a um importante processo de (re)construção biográfica, com efeitos formativos. A (re)construção biográfica resulta num importante processo de formação, tendo-se em vista que o adulto realiza "uma longa busca de si” (DOMINICÉ, 2006, p. 345), com consequências na dimensão existencial, ou seja, "no modo de estar no mundo" (RICOEUR, 1985, p. 119). Este efeito formativo do processo é muito significativo, porque apresenta um elevado potencial de transformação nos adultos.

O acompanhamento realizado durante o processo de reconhecimento e validação de adquiridos experienciais é um domínio de inovação estruturante na organização e no funcionamento deste tipo de prática - complexa, desconhecida e difícil para os adultos. A biografização e a escrita da narrativa biográfica exigem o acompanhamento por parte de profissionais com formação específica e com experiência nesta abordagem metodológica. Estes profissionais apoiam o adulto na superação das dificuldades de reflexão, de rememoração, de seleção e de explicitação da experiência de vida e dos adquiridos experienciais. Além disso, apoiam o adulto no processo de escrita e na articulação entre os seus adquiridos experienciais e os elementos que constam nos referenciais de competênciaschave. O acompanhamento é um domínio fundamental para o reconhecimento de adquiridos experienciais, porque permite assegurar a dialética entre o autorreconhecimento e o heteroreconhecimento. $\mathrm{O}$ processo de reconhecimento e validação de adquiridos experienciais assente na biografização e no acompanhamento permite aos adultos apropriarem-se do percurso de vida, da experiência, dos saberes e do processo de formação. Nesse sentido, assumem-se como sujeitos capazes, com autonomia e com poder para agir no mundo que os rodeia. 


\section{Referências}

AUBRET, Jacques; MEYER, Nicole. La reconnaissance des acquis personnels et professionnels et l'enseignement supérieur, les enjeux. Paris: Université de Paris VIII, 1994. Collection thématiques - Formation/ Permanente.

BERGER, Guy. A experiência pessoal e profissional na certificação de saberes: a pessoa ou a emergência de uma sociedade global. In: PORTUGAL. Ministério da Educação (org.) Novos rumos para o Ensino Tecnológico e Profissional. Porto: ME, 1991. p. 233-243.

CANÁRIO, Rui. O que é a Escola - Um olhar sociológico. Porto: Porto Editora, 2005.

CANÁRIO, Rui. Uma problemática para o estudo do RVAE. Formação e adquiridos experienciais: entre a pessoa e o indivíduo. In: FIGARI, Gérard; RODRIGUES, Pedro;

ALVES, Maria Palmira; VALOIS, Pierre (org.). Avaliação de competências e aprendizagens experienciais. Saberes, modelos e métodos. Lisboa: Educa, 2006. p. 35-46.

CAVACO, Carmen. Adultos pouco escolarizados. Políticas e práticas de formação. Lisboa: Educa e UIDCE.

COMISSÃO EUROPEIA. Livre blanc sur l'éducation et la formation. Enseigner et Apprendre. Vers la société cognitive. Luxemburgo: Comissão Europeia, 1995.

COMISSÃO EUROPEIA. Eurydice. Educação e Formação de Adultos. Aspetos gerais do sistema de educação e formação de adultos. Agência Executiva relativa à Educação, ao Audiovisual e à Cultura, [S. l.], 16 jan. 2019. Disponível em: https://bit.ly/34AisVr. Acesso em: 29 jun. 2019.

DELORY-MOMBERGER, Christine. De la recherche biographique en éducation. Fondements, méthodes, pratiques. Paris: Téraèdre, 2014.

DESLAURIERS, Jean-Pierre; KERISIT, Michèle. Le devis de recherche qualitative. In: POUPART, Jean et al. La Recherche qualitative. Enjeux épistémologiques et méthodologiques. Montréal: Gaëtan Morin, 1997. p. 85-111.

DOMINICÉ, Pierre. A formação de adultos confrontada pelo imperativo biográfico, Educação e Pesquisa, São Paulo, v. 32, n. 2, p. 345-357, ago. 2006. ISSN 1517-9702. http://dx.doi.org/10.1590/S1517-97022006000200010.

https://bit.ly/2PXGoMO. Acesso em: 20 set. 2018.

FINGER, Matthias; ASÚN, José M. A Educação de Adultos numa encruzilhada. Aprender a nossa saída. Porto: Porto Editora, 2003.

GIL, José. O que não sabemos sobre nós. O vazio das não notícias. Público, Lisboa, 5 de mar. 2012. Disponível em: http://static.publico.pt/docs/sociedade/03.pdf. Acesso em: 20 set. 2018.

GIORGI, Amedeo. De la méthode phénoménologique utilisée comme mode de recherche qualitative en sciences humaines: théorie, pratique et évaluation. In: POUPART, Jean et al. La Recherche qualitative. Enjeux épistémologiques et méthodologiques. Montréal: Gaëtan Morin, 1997. p. 341-364.

JOBERT, Guy. Les difficiles questions adressées par la VAE à l'analyse du travail. In: 
ROZARIO, Pascal (ed.). Enjeux politiques et systèmes de reconnaissance des apprentissages. Paris: CNAM, 2005. p. 7-15. Actes du Colloque Européen, v. 2.

LAPERRIÈRE, Anne. La théorisation ancrée (grounded theory): démarche analytique et comparaison avec d'autres approches apparentées. In: POUPART, Jean et al. La Recherche qualitative. Enjeux épistémologiques et méthodologiques. Montréal: Gaëtan Morin, 1997. p. 309-340.

LE BOUËDEC, Guy. La démarche d'accompagnement, un signe des temps. Education Permanente, Paris, n. 153, p. 13-20, dec. 2002. Disponível em: https://bit.ly/2rMhDvn. Acesso em: 20 set. 2018.

LIÉTARD, Bernard. Se reconnaître dans le maquis des acquis. Education Permanente, Paris, n. 133, p. 65-74, 1997. Disponível em: https://bit.ly/34qYgVT. Acesso em: 20 set. 2018.

LIÉTARD, Bernard; PIAU, Anne; LANDRY, Pierre (coord.). Pratiquer la reconnaissance des acquis de l'expérience. Lyon: Chronique Sociale, 2017.

MEZIROW, Jack. Penser son formation. Développer l'autoformation. Lyon: Chronique Sociale, 2011.

MUCCHIELLI, Alex (org.). Dictionnaire des méthodes qualitatives en sciences humaines et sociales. Paris: Armand Colin, 2002.

ORGANIZAÇÃO DAS NAÇÕES UNIDAS PARA A EDUCAÇÃO, CIÊNCIA E CULTURA (UNESCO). V Conferência Internacional sobre a educação de adultos. Declaração de Hamburgo. Brasília: Editora do Sesi, 1999. (Série Sesi/Unesco Educação do Trabalhador $\left.n^{0} 1\right)$.

PINEAU, Gaston. A autoformação no decurso da vida: entre a hetero e a ecoformação. In: NÓVOA, António; FINGER, Matthias (org.). O método (auto)biográfico e a formação. Lisboa: Ministério da Saúde, 1988. p. 65-86.

PINEAU, Gaston. La reconnaissance des acquis: deux idées simples qui posent des problèmes complexes. In: PINEAU, Gaston; LIETARD, Bernard; CHAPUT, Monique (coord.). Reconnaître les acquis. Démarches d'exploration personnalisée. Paris: L'Harmattan, 1997. p. 11-17.

PIRES, Ana Luísa. Educação e formação ao longo da vida: análise crítica dos sistemas e dispositivos de reconhecimento e validação de aprendizagens e de competências. Lisboa: Fundação Calouste Gulbenkian, 2005.

PORTUGAL. Conselho Nacional de Educação. Estado da Educação 2011. A Qualificação dos Portugueses. Lisboa: CNE, 2011.

PORTUGAL. Ministério da Educação. Direção-Geral de Estatísticas da Educação e Ciência. Educação em Números - Portugal 2018. Lisboa: DGEEC, 2018. Disponível em: https://bit.ly/2Ptz908. Acesso em: 29 jun. 2019.

RICOEUR, Paul. Temps et récit. Le temps raconté. Paris: Éditions du Seuil, 1985.

RICOEUR, Paul. Parcours de la reconnaissance. Paris: Éditions Stock, 2004. 
RICOEUR, Paul. Devenir capable, être reconnu. Esprit, [S. l.], n. 7, juil. 2005. Não paginado. Disponível em: https://bit.ly/2RYErTb. Acesso em: 29 jun. 2019.

ROSE, Nikolas. Powers of freedom: reframing political thought. Cambridge: Cambridge University Press, 1999.

SANSREGRET, Marthe. La reconnaissance des acquis. Principes. Montreal: Éditions Hurtubise HMH, 1988.

SCHURMANS, Marie-Noëlle. Expliquer, interpréter, comprendre. Le paysage épistémologique des sciences sociales. Genève: Université de Genève, 2006.

SCHURMANS, Marie-Noëlle . Restitution et épistémologie, Sociologies, [S. l.], jun. 2014. Não paginado. Disponível em: http://journals.openedition.org/sociologies/4716. Acesso em : 29 jun. 2019.

SOCIEDADE PORTUGUESA DE CIÊNCIAS DA EDUCAÇÃO. Instrumento de Regulação Ético-Deontológica. Carta Ética. Porto: SPCE, 2014. Disponível em: https://bit.ly/2YZ6ymQ. Acesso em: 29 jun. 2019. 